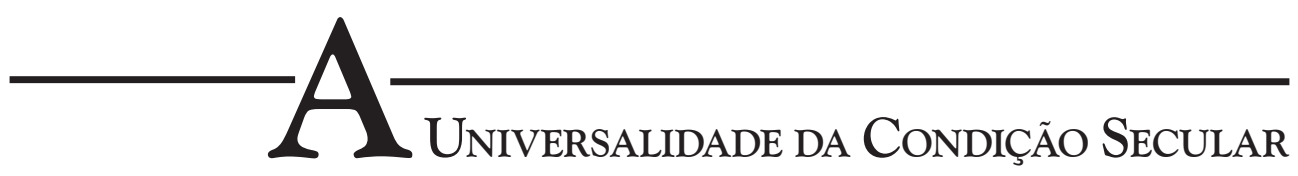

Roberto Dutra Universidade Estadual do Norte Fluminense Darcy Ribeiro - Campos dos Goytacazes Rio de Janeiro - Brasil

\title{
Introdução
}

O conceito de secularização tornou-se problemático tanto na sociologia da religião como na teoria da sociedade. Com a evolução da sociedade moderna no século XX, a tese do declínio da religião (desinstitucionalização, privatização, etc.) - o significado mais difundido do conceito - tornou-se obsoleta. Tomando o conjunto dos países inequivocamente classificados como pertencentes à modernidade ocidental, e excetuando a Europa, pode-se dizer que não apenas a busca pelas religiões não declinou com a modernidade, como também que a esfera religiosa ganhou vigor e caráter especificamente modernos, assumindo em alguns contextos papéis importantes na identificação coletiva de grupos e camadas sociais e adquirindo inclusive graus de "efervescência" e "devoção" atípicas para o pertencimento religioso tradicional, fundado muito mais no ancoramento político e territorial do que no engajamento individual com as práticas e crenças sagradas (Luhmann 2002:301-302).

Neste contexto, a problematização do conceito de secularização vem girando em torno de seu significado preciso e de sua utilidade para a compreensão da relação entre religião e sociedade no mundo contemporâneo. O que realmente devemos entender por secularização? Qual o significado atual da secularização para a relação entre a vida religiosa e a vida social como um todo? Como ressalta Casanova (2010:265), é do filósofo canadense Charles Taylor, em seu livro A Secular Age, o esforço contemporâneo mais sistemático, tanto em termos conceituais como históricos, de enfrentar estas duas questões sociológicas centrais sobre o conceito de secula- 
rização. Antes mesmo de tratar do conteúdo da empreitada tayloriana, vale enfatizar desde já que, metodologicamente, seu caminho é o mesmo que iremos seguir neste texto: reconstruir o conceito de secularização com parte da reconstrução do próprio conceito de sociedade moderna. Se as previsões sobre o declínio da religião eram falsas, é porque não só a sociologia da religião errou, mas também porque a teoria da sociedade não construiu uma compreensão satisfatória da sociedade moderna capaz de abarcar a efetividade da modernidade religiosa.

O objetivo deste artigo é refazer o caminho traçado por Taylor com um instrumental teórico ainda pouco utilizado para tratar do tema da secularização: a teoria da sociedade de Niklas Luhmann. Essa teoria fornece elementos robustos tanto para definir de forma precisa o conceito de secularização como também para apreender o seu significado para as relações entre religião e sociedade no mundo atual. A tese central é que a secularização deve ser concebida como a principal consequência da diferenciação dos subsistemas sociais para a vida religiosa, podendo ser definida como a necessidade, enfrentada por toda e qualquer religião deste mundo, de ter que construir suas crenças e práticas em um mundo ordenado por referências não religiosas.

A contribuição está estruturada em quatro seções. Na primeira, discutimos a relação entre secularização e modernidade e avaliamos os impasses e desafios do conceito para lidar com a condição da religião no mundo contemporâneo. Na segunda seção, discutimos a teoria sociológica da secularização de Niklas Luhmann, buscando demonstrar que um uso preciso do conceito de secularização exige conferir centralidade à diferenciação funcional da sociedade como traço definidor da modernidade. Na terceira seção, acrescentamos um componente decisivo e cheio de consequências para o conceito de secularização: seu caráter global. Se a sociedade moderna, funcionalmente diferenciada, só pode ser entendida no singular, como sociedade mundial, o mesmo vale para o conceito de secularização. Como a diferenciação da sociedade em subsistemas funcionais não obedece fronteiras territoriais, todo e qualquer fenômeno, movimento ou organização religiosa, mesmo em um Estado teocrático, é obrigado a lidar com um ambiente societal ordenado por valores, normas, interesses e identidades sociais de natureza não religiosa. Se nenhuma religião é capaz de forjar para si um entorno social ordenado exclusivamente por uma lógica religiosa, então a secularização tornou-se uma categoria de validade universal. $\mathrm{Na}$ quarta e conclusiva seção, usamos nosso argumento para dar uma contribuição ao debate sobre a concepção de "secularidades múltiplas" (Wohlrab-Sahr \& Burchardt 2012), enfatizando a relação entre a unidade da condição secular moderna e a variedade de casos concretos.

\section{Secularização e modernidade}

O conceito de secularização é inseparável do conceito de modernidade. Demarca o tipo de relação entre religião e sociedade característica da era moderna. $\mathrm{O}$ 
consenso básico em torno do conceito diz respeito à transição para a modernidade: o mundo moderno rompe com o monopólio religioso de instituir uma visão de mundo totalizante, capaz de abarcar todo o conjunto das esferas sociais. No entanto, o significado e as consequências dessa ruptura para a relação entre religião e sociedade no desenvolvimento subsequente da sociedade moderna não têm sido matéria consensual. Se, no alvorecer da modernidade, a sociologia herdou a tese iluminista do declínio da religião, a evolução da modernidade refutou-a. Seja porque o conceito de modernidade não pode mais ser reduzido ao Ocidente, seja porque o próprio ocidente não confirma a tese do declínio da religião, o fato é que o desenvolvimento da modernidade desafiou e continua desafiando o conceito de secularização.

Resta daí a questão decisiva de se e como esse conceito ainda pode servir para compreender o lugar da religião na modernidade. Possui o conceito de secularização algum significado mais profundo, não redutível à tese do declínio, que o torna necessário para compreender a relação entre religião e sociedade? Seria esse conceito capaz de contribuir na compreensão de realidades tão diversas no que concerne ao vigor, à difusão e aos diferentes modos existentes de estruturar a relação entre religião e sociedade?

Como a teoria da modernização e suas premissas de difusão e convergência em torno de um modelo similar de diferenciação e organização social baseado na democracia parlamentar, no Estado de direito, na economia liberal de mercado, na ciência racional e no confinamento da religião à esfera privada se revelaram equivocadas, a busca de um conceito geral de secularização tende a ser vista como necessariamente comprometida com o normativismo eurocêntrico incapaz de dar conta da diversidade de situações envolvendo o tema (Wohlrab-Sahr \& Burchardt 2012:877). Abandonar pretensões de generalização parece ter se tornado a regra.

Neste contexto, a obra monumental do filósofo canadense Charles Taylor A Secular Age é uma exceção. Para Casanova (2010:265), trata-se da "melhor abordagem analítica, fenomenológica e genealógica que possuímos sobre nossa condição secular moderna”. O objetivo maior desta empreitada é colocar a autocompreensão secular do mundo moderno no centro da discussão e com isso demarcar seu caráter contingente e historicamente excepcional. Apesar de Taylor tratar especificamente do desenvolvimento societal e religioso do Ocidente, seu argumento principal desemboca na tese de que a condição secular representa para todos nós que vivemos em uma única e mesma era moderna uma ruptura radical com a concepção de mundo présecular. Esta assertiva generalizante, apoiada no fato histórico da expansão da condição moderna por todo o globo, não implica em negar a variabilidade de configurações da relação entre religião e sociedade.

Para Taylor (2007), o núcleo generalizável do conceito de secularização não é nem a diferenciação funcional (secularidade 1) - o que inclui a privatização da religião -, nem a decadência da religiosidade individual (secularidade 2), mas antes a construção de um novo "quadro de compreensão imanente", de um novo "hori- 
zonte cultural" que reorienta tanto as práticas religiosas como as não religiosas. Esta concepção "culturalista" da secularização tem o mérito de articular (para usar um termo central em Taylor) o horizonte compartilhado na era secular, ou seja, o pano de fundo de problemas sociocognitivos e socionormativos que se impõe a todo tipo de prática religiosa e não religiosa. No entanto, como veremos em seguida, esse horizonte cultural compartilhado na era secular, diferente da ênfase conferida por Taylor, só é explicável se levarmos em conta sua vinculação com o processo de diferenciação funcional da sociedade. É que os problemas estruturais comuns da era secular, sejam eles de natureza cognitiva, sejam de natureza normativa, resultam do primado dessa forma de diferenciação societal. No caso do conceito de secularização, trata-se de um modo de autocompreensão e autodescrição que demarca os problemas decorrentes do fato de a pertença e a vida religiosa terem se tornado questões contingentes no mundo moderno.

Não nos interessa aqui discutir como a antropologia filosófica de Taylor (1992) influencia sua abordagem da secularização (Koenig 2011). Basta ressaltar que sua concepção de homem implica em uma noção antropológica da religião segundo a qual a diferença entre transcendência e imanência não é apenas um artefato social comunicativamente construído (como em Luhmann), mas uma referência cultural enraizada na busca por sentido e orientação moral substantiva como características invariantes da condição humana. Para ele, a dimensão transcendente refere-se antes de tudo à transcendência das metas de vida humanas em favor de metas últimas como a vontade e o amor divinos. Mesmo que a religião em si não seja percebida como uma "constante antropológica", como uma invariante histórica, é inegável que, para Taylor, ela aparece como a forma mais robusta de resposta à "constante antropológica" que é a busca por sentidos e orientações morais substantivas, ou seja, por "distinções qualitativas" e concepções da "vida plena" social e culturalmente aceitas como válidas. Nesse sentido, sua abordagem aproxima-se bastante da tradição de Durkheim e Parsons, a qual enfatiza o caráter socialmente integrador da religião, enquanto fonte moral privilegiada, posto que fundada no caráter transcendente das metas de vida socialmente valoradas.

Desse modo, a virada histórica caracterizada pela condição secular consiste no fato de o "humanismo exclusivo" (Taylor 2007:18ss) ter rompido o monopólio dos valores transcendentes na orientação moral da identidade e da agência humanas, ou seja, o fato de "o florescimento humano" em diferentes dimensões e esferas imanentes (como "razão", "sentimento", etc.) ter se tornado a meta de vida absoluta a qual as práticas religiosas e não religiosas terão que levar em conta. Como agora é possível ter uma vida significativa mesmo sem referência a valores transcendentais, a descrença tornou-se uma opção de vida normal em nosso mundo. A fé religiosa não é mais o caminho autoevidente para a busca de sentido e orientação moral. Para Taylor, é exatamente isto que define a condição secular em sua vinculação mais profunda com o "quadro de compreensão imanente", aquilo que ele denomina "secularidade 3". 
Na visão de Taylor, o imaginário pré-secular era baseado em um encadeamento implícito de noções sobre o mundo em diferentes dimensões. Como podemos ver na cristandade medieval, a concepção da fé como modo de vida incontornável e não escolhido pressupunha noções muito específicas sobre o mundo natural, subjetivo e social. $\mathrm{O}$ mundo natural era percebido como cosmos e criação de Deus, o mundo subjetivo como aberto aos efeitos de forças transcendentais (porous self), e o mundo social como formado por uma hierarquia ancorada numa ordem e numa temporalidade transcendentes, inalteráveis pela intervenção humana.

A tese de Taylor é que a condição secular emerge de uma desconstrução encadeada destas três noções: o mundo natural passa a ser visto como um universo mecânico regido por leis impessoais e independentes de vontades sobrenaturais; o mundo subjetivo como fechado (buffered self) a essas vontades; e o mundo social passa a ser imaginado como uma sociedade à qual todos têm acesso direto e cuja história transcorre de acordo com um futuro em aberto e não como desdobramento de uma temporalidade transcendental pré-fixada. Disso resulta o que ele vai chamar de "quadro imanente", ou seja, o horizonte cultural compartilhado no qual crença e descrença surgem como opções, não podendo mais a crença ser percebida ingenuamente como a única forma de vida possível.

A abordagem de Taylor contribui para desnaturalizar o "quadro imanente" e a "condição secular", ou seja, para superar a fraca consciência da contingência histórica que caracteriza a maior parte das teorias da secularização em sua afinidade com doutrinas político-normativas que não costumam relativizar a condição secular. Além disso, como na abordagem de Luhmann, Taylor nos traz uma alternativa às "narrativas da subtração" (Taylor 2007:26) que descrevem a "condição secular" unicamente como perda de espaço para a religião. Contra essas narrativas, Taylor busca reconstruir a relação entre religião e mundo secular com o intuito de demonstrar as formas especificamente modernas de vitalidade e organização religiosas, ainda que estas convivam com tendências opostas de esfriamento e desinstitucionalização. A religião "permanece uma força motivacional independente na modernidade" (Taylor 2007:530).

Taylor adota uma linha de argumentação semelhante à sociologia da religião de Weber, enfatizando o esforço reformador de diversas organizações religiosas cristãs em superar a dicotomia entre a religiosidade virtuosa das elites e a religiosidade frouxa dos leigos. O resultado é um racionalismo religioso de caráter disciplinador em quase todas as esferas sociais, motivado pela crença de que o homem é instrumento para realizar a obra divina neste mundo. Na visão de Taylor, assim como em Weber, esse racionalismo religioso contribuiu, paradoxalmente, para a formação de novas organizações, elites e grupos econômicos, políticos, científicos, parcialmente livres da hierarquia eclesiástica, os quais, a partir dos séculos XVI e XVII, deram suporte a lógicas específicas que vão reger o funcionamento das esferas que iam paulatinamente se autonomizando da religião. No século XVIII, a grande virada acontece: a virada antropocêntrica completa-se com o distanciamento de Deus em relação à sua criação 
e a entronização do "florescimento humano" como meta de vida absoluta nas esferas sociais que agora passam a funcionar movidas unicamente pelo que Taylor chama de "humanismo exclusivo", sem a necessidade de uma motivação religiosa.

Decisivo para Taylor é o fato de o "quadro imanente" e a condição secular não significarem necessariamente uma decadência da fé, mas antes o surgimento de novas formas de vida religiosa. Os inegáveis fenômenos de decadência do religioso, assim como as tendências correspondentes de desinstitucionalização e individualização, constituem apenas episódios e variantes de desenvolvimento em uma história mais ampla e complexa que também inclui tendências opostas de revitalização da religião, inclusive de seu papel na vida pública e de suas formas organizacionais (Koenig 2011:662). Os movimentos de renovação e as missões religiosas nos Estados Unidos do século XIX, a formação de milieus confessionais na Europa do mesmo período e, sobretudo, o pentecostalismo e o islamismo revitalizado do século XX são formas especificamente modernas assumidas pela religião, ou seja, formas que pressupõem um "quadro imanente" marcado pela contingência da religião diante de outras esferas sociais e de um mundo que não é ordenado por categorias exclusivamente religiosas. Como Koenig (2011) admite, a teoria dos sistemas também é capaz de combinar realidades de declínio e esfriamento com realidades de revitalização do religioso como fazendo parte da mesma história moderna da religião em uma condição secular.

O que nos interessa aqui é o fato de a abordagem tayloriana, mesmo não dando devida atenção à noção de diferenciação funcional para a definição da condição secular, enfatizar uma transformação na concepção de mundo na passagem à modernidade secular que só pode ser compreendida com a ajuda da teoria sociológica da diferenciação funcional, a qual coloca em primeiro plano a destruição da concepção pré-moderna e totalizante de mundo por meio dos diferentes "mundos" criados pelos sistemas sociais diferenciados. Sem levar em conta a fragmentação societal em diferentes domínios autonomizados de práticas não se consegue compreender adequadamente a ruptura com a visão totalizante de mundo que colocava a pertença religiosa como forma incontornável e necessária de participação social e construção da vida plena. Taylor nos fornece a reconstrução do imaginário secular moderno, daquilo que Luhmann chamaria de semântica, mas precisamos vincular esse imaginário à dimensão estrutural da forma como a sociedade se diferencia em subsistemas ou esferas autônomas. A divisão proposta por Taylor para a "condição secular" (religiosidade individual, diferenciação das esferas e contingência da fé) corresponde à tripartição de Peter Berger (1967) que declina a secularização nos níveis da consciência individual, das instituições da sociedade e das visões de mundo culturais. No entanto, a ênfase recai quase que unilateralmente no nível da cultura, negligenciando especialmente o papel complementar da diferenciação funcional ou institucional. Em seguida, tentaremos contribuir para a correção dessa visão unilateral, valendo-se da teoria da sociedade de Niklas Luhmann. 


\section{Secularização e diferenciação funcional}

A teoria da diferenciação das esferas, por muito tempo o núcleo inquestionável da tese da secularização, hoje também é bastante criticada, especialmente as variantes que afirmam uma progressiva diferenciação entre as esferas e seu convívio crescentemente pacífico como telos convergente da evolução social. Na tentativa de reagir a essas críticas, a concepção de "modernidades múltiplas" (Eisenstadt 2000), ponto de partida para o conceito de "múltiplas secularidades", enfatiza as múltiplas formas assumidas pela diferenciação das esferas sociais. No foco estão as diferentes formas regionais e nacionais de diferenciação e integração entre a religião e a sociedade. Nessa mesma direção, cabe ressaltar que a reconstrução tayloriana do "quadro imanente" que define a condição secular permite enriquecer a compreensão da diferenciação entre religião e sociedade na modernidade ocidental (Koenig 2011:664). A emergência de esferas públicas autônomas, de economias de mercado e de comunidades nacionais e Estados soberanos como condição necessária para a imaginação de um tempo histórico separado da história da salvação e de um mundo social desacoplado da hierarquia religiosa demonstra claramente como a diferenciação da sociedade em esferas autônomas não pode faltar na explicação da condição secular moderna. No entanto, Taylor não reconstrói o vínculo entre imaginário secular e diferenciação da sociedade. A reconstrução desse vínculo não precisa se valer de uma abordagem etapista que apregoa a convergência entre os diferentes contextos regionais, nacionais ou sociais que vivenciam e ressignificam a diferenciação funcional, como se ao fim e ao cabo fosse se completar a difusão, por todas as regiões do globo, de uma única e mesma forma de organizar a relação entre religião e os diferentes subsistemas sociais autonomizados.

Ao abandonar qualquer viés teleológico, a teoria da diferenciação funcional de Luhmann revela-se capaz de nos fornecer uma compreensão mais ampla da condição secular moderna, que leve em conta as diferentes formas assumidas pela diferenciação entre religião e sociedade. Ao invés de, por exemplo, seguir o caminho pré-fixado de uma retirada crescente da religião do espaço público como correlato necessário da diferenciação entre religião e política, a abordagem luhmanniana deixa em aberto se e como a religião assume formas mais ou menos potentes na vida social moderna: não há telos, seja este entendido em termos de declínio, de privatização, seja de desinstitucionalização; há sim evolução comandada por dose incontornável de contingência e acaso ${ }^{1}$. Portanto, diferenciação funcional e secularização, ao contrário de serem tratadas como ponto de chegada (telos) e modelo convergente para a relação entre religião e sociedade, são o ponto de partida para se compreender as diferentes formas e tendências (muitas vezes contraditórias) assumidas pelo desenvolvimento da religião na modernidade.

Essa perspectiva antiteleológica traz outra grande vantagem para se compreender a condição secular moderna: o caráter indutivo da teoria da diferenciação funcional. Em oposição, por exemplo, a Parsons $(1951,1974)$, que concebe a diferenciação 
funcional dedutivamente como a especialização de funções societais pré-estabelecidas (as famosas quatro funções do esquema AGIL)2 ${ }^{2}$, Luhmann parte da premissa indutiva (e antiteleológica) de que as funções socialmente relevantes são produto contingente e histórico da própria evolução da sociedade; é a formação de sistemas funcionais (por meio do processo de diferenciação) que produz as funções sociais, e não o contrário. Isto significa dizer que o leque de sistemas funcionais deve ser concebido como aberto. Para a compreensão da condição secular o ganho está na possibilidade de superar a dicotomia simplista religião/Estado como fórmula para se apreender a diferenciação das esferas. Avessamente a abordagens como a de Pierucci (2008:12), que restringem a secularização à diferenciação entre Igreja e Estado, a perspectiva luhmanniana enfatiza que, com a diferenciação funcional, esferas como educação, medicina, comunicação de massas, artes, etc. também integram o mundo secularizado, ou seja, o mundo ordenado por racionalidades autonomizadas da religião.

Como veremos mais à frente, para Luhmann o conceito de secularização tem no próprio sistema da religião sua referência constitutiva. Secularização designa a forma como o mundo social funcionalmente diferenciado aparece na perspectiva da religião. Enquanto o conceito de religião registra uma demarcação entre o universo religioso e o universo mundano, o conceito de secularização serve para caracterizar o universo mundano como ordenado por lógicas diferenciadas da visão de mundo religiosa.

Antes de analisarmos mais detalhadamente a secularização como consequência da diferenciação funcional, é importante abordar a própria diferenciação funcional da religião. No que se refere à relação entre religião e sociedade na Europa, pode-se dizer que entre os séculos XI e XVIII, ainda em uma sociedade pré-moderna feudal e estamental, se verifica uma diferenciação da religião como esfera social própria que tanto vai limitar como incentivar a diferenciação de outras esferas, como a economia, a política, a arte e a ciência (Luhmann 2002:285). A religião - e nisto Weber (1989) e Luhmann estão de acordo - foi a primeira esfera de valor (ou sistema funcional) a se diferenciar do restante do mundo social. No entanto, essa diferenciação não levou à formação de um conjunto de esferas de valor autônomas (que só ocorreria na transição para a modernidade, especialmente depois da Reforma). Ao invés de se afirmar como uma esfera de valor entre outras, a religião pré-moderna impôs-se como a esfera central de toda a ordem cosmológica, abarcando, por meio de uma interpretação unitária de mundo, também as demais esferas sociais. Neste sentido, a autonomização dessas outras esferas (como a política, a ciência, a economia, a esfera erótica e a esfera artística) vai ser conquistada como uma autonomização em relação à religião, sendo esta, no processo de transição para a modernidade, muito mais "vítima" do que "protagonista" do processo de diferenciação da sociedade. O protestantismo ascético, ao radicalizar a tensão entre religião e mundo e ao pretender reconstruir a regulamentação da conduta de vida nas esferas de valor mundanas com base em motivações e normas religiosas, já evidencia esta condição da esfera religiosa enquanto "vítima" do processo de diferenciação da sociedade. Trata-se de um esforço para retomar o terreno perdido para o 
mundo, esforço este que, ao construir um sentido religioso que sacraliza o valor moral do engajamento com profissões e atividades mundanas, acaba (como aponta Weber com sua fórmula do "paradoxo das consequências") por favorecer o processo de diferenciação das esferas de valor que se queria evitar.

No caso da Europa, a esfera religiosa, tendo sido a primeira a se autonomizar e se diferenciar do restante do mundo social, vai desenvolver mecanismos simbólicos e institucionais para garantir a integração religiosa da conduta de vida em todos os âmbitos sociais, especialmente naqueles que mais entravam em choque com a racionalidade específica da religião: a economia, a política, as artes e a ciência (Schneider 2011:190-199). O que vai, entre outras coisas, garantir essa integração é a alternativa de não radicalizar a tensão entre religião e mundo para a conduta de vida dos "leigos", criando formas variadas de acomodação entre as exigências religiosas e as exigências mundanas, as quais, como se pode ver no exemplo paradigmático das indulgências, vão permitir neutralizar constante e ininterruptamente os riscos que a conduta de vida orientada por valores e interesses mundanos poderia trazer para o destino religioso (a salvação ou a condenação) dos indivíduos. Neste contexto, a radicalização entre a ética religiosa e as exigências mundanas fica restrita à conduta de vida de uma minoria de virtuosos, sendo o ascetismo extramundano monacal sua expressão típica. As massas, especialmente as massas do mundo rural e feudal, não vivenciavam a religião racionalizada e, por conta disso, colocada em tensão com o mundo, o que foi indispensável para permitir a integração religiosa da conduta de vida. Em resumo, a integração religiosa da conduta de vida não decorre da radicalização do potencial de autonomização da esfera religiosa e sua contraposição ao mundo, mas antes da contenção desse potencial por meio de mecanismos de acomodação entre as exigências ético-religiosas e as esferas mundanas.

Com a Reforma religiosa ocorre justamente o oposto. Especialmente o protestantismo ascético, ao radicalizar a rejeição ética do mundo e acentuar a tensão entre imanência e transcendência, acaba contribuindo para a diferenciação da religião em relação a outras esferas de valor. Depois de tentativas fracassadas de reconciliar confissão religiosa e dominação política, a Reforma resulta em uma efetiva separação entre essas duas esferas. O protestantismo ascético, por sua vez, além de contribuir decisivamente na construção de uma ética do trabalho profissional intramundano, favorecendo o engajamento do indivíduo com as atividades e profissões formadas no bojo da diferenciação das esferas sociais, leva a uma individualização da experiência religiosa, a qual passa a ter o sentido de decisão e convicção individual desritualizada e solitária, ainda que o processo de desritualização não tenha a última palavra, sendo obrigado a conviver com novas ritualidades com as quais as organizações religiosas ensejam e estruturam a decisão individual pela fé (o pentecostalismo é um importante exemplo disto).

No nível macrossociológico (aqui preenchido pelas esferas de valor como dimensão mais abstrata da ordem social), o resultado evolutivo é que, da perspectiva religiosa, a sociedade se bifurca entre um lado religioso e outro não religioso. Neste 
sentido, o conceito de secularização marca a tentativa da religião de se recolocar em um ambiente social diferenciado em esferas que não seguem valores religiosos, mas sim suas legalidades próprias (Eigengesetzlichkeiten). O maior equívoco no uso do conceito de secularização foi, possivelmente, deduzir da diferenciação entre religião e sociedade no nível macro das esferas de valor assertivas o desaparecimento do religioso tanto no nível meso das organizações e agrupamentos religiosos (e sua perda de influência, como no caso da Europa) como no nível micro das interações cotidianas e da religiosidade individual.

$\mathrm{O}$ aprofundamento da diferenciação entre religião e sociedade e a crescente incompatibilidade entre as expectativas e exigências de conduta religiosas e mundanas representam um desafio para a religião. Ocorre, por exemplo, a partir do século XVIII - o "século da teodiceia" (Geyer 1982) -, uma radicalização do problema da teodiceia, culminando em um questionamento moral da justiça divina. A religião é confrontada com métricas e valores não religiosos. Neste sentido, o problema da teodiceia deve ser entendido como historicamente contingente, e não como uma questão constante de toda e qualquer religião (como parece ser o caso em Weber): trata-se de um questionamento da justiça divina a partir de moralidades seculares, diferenciadas da religião, um fenômeno que tanto resulta da como promove a diferenciação funcional da sociedade.

Esta tensão macrossocietal entre religião e mundo não afeta apenas o nível micro da personalidade individual como enfatizou Weber, manifestando-se também no nível intermediário (meso) das organizações religiosas. Não apenas os indivíduos veem a sua religiosidade confrontada com exigências mundanas endereçadas ao seu estilo e condução da vida. Também as organizações religiosas têm sua religiosidade desafiada por exigências estruturais (cognitivas e normativas) de natureza mundana (economia, direito, mídia, política, família, etc.).

No entanto, apesar de Weber ter elaborado uma sociologia das organizações (enquanto sociologia das organizações burocráticas) com pretensões explicativas sobre diferentes esferas de valor e uma tipologia das organizações especificamente religiosas (a tipologia Seita-Igreja), ele não tematiza a tensão entre religião e mundo que se instala neste nível mesossociológico. A relação entre religião e as demais esferas de valor (seja esta uma relação de tensão, de acomodação/adaptação, seja mesmo de afirmação mútua) é percebida e tematizada unicamente no nível da personalidade individual. Para Weber, a tensão (como forma específica de relação, mas não a única) entre religião e o mundo estava situada em um contexto mais amplo definido pelo imperativo de ter que decidir individualmente pela adesão vocacional a uma entre as diversas esferas de valor autonomizadas. Todo o problema da diferença entre as vocações do cientista e do político, assim como o diagnóstico trágico do "homem do prazer sem coração" (Genussmenschen ohne Herz) e do "especialista sem espírito" (Fachmenschen ohne Geist), está em Weber, ainda que nem sempre de forma sistemática e explícita, vinculado ao significado e às consequências da diferenciação das esferas de valor para a personalidade individual. 
A falta de devida atenção ao tema das organizações religiosas compromete, porém, a tentativa de compreender o significado e as consequências da diferenciação das esferas de valor para o modo como a religião se recoloca na sociedade, interpretando religiosamente (por meio de referências ao transcendente como fonte de sentido do imanente) as necessidades de indivíduos cujas vidas são conduzidas em diferentes esferas de valor. Se na sociedade pré-moderna era a moral estamental (com as respectivas concepções de "boa vida" vigentes para cada estamento específico) que criava e estabilizava os vínculos entre as exigências religiosas e as exigências mundanas, na sociedade moderna essa função vai ser desempenhada pelas organizações religiosas. Se antes nascer em um estamento ${ }^{3}$ tinha implicações diretas sobre o modo como a regulação religiosa da vida haveria de ser compatibilizada com os imperativos (militares, econômicos, sexuais, etc.) profanos endereçados ao indivíduo, agora é a condição de ser ou tornar-se membro de uma organização religiosa que vai definir a relação entre fé e a conduta de vida nas esferas sociais mundanas. Enquanto base simbólica sobre a qual a religião vai se diferenciar de outras esferas sociais, a fé permite que as organizações religiosas - sobretudo as "comunidades de fé" (Glaubensgemeinschaften) - se autonomizem em relação aos vínculos de pertencimento estamental, étnicos e de parentesco (Schneider 2011:184); mas o significado da fé para a conduta de vida mundana varia com o tipo de organização religiosa, especialmente com o formato das exigências e expectativas comportamentais vinculadas à condição de membro.

A importância das organizações enquanto sistema social de tipo próprio está diretamente ligada aos desafios trazidos pela diferenciação funcional e pela secularização. Apesar de reconhecer seu eurocentrismo, especialmente sua vinculação com o programa filosófico-político secularista de reduzir a influência da Igreja na sociedade, Luhmann não defende abandonar o conceito de secularização. $O$ caminho para livrá-lo da visão eurocêntrica passa por recuperar sua vinculação com o significado do termo latim saeculum na tradição ocidental: a designação católica para o mundo necessitado de salvação, afundado no pecado e no sofrimento. Este significado original é atual, pois o mais importante no conceito é a demarcação de uma esfera mundana em tensão com a religião. A secularização não é um processo de privatização, desinstitucionalização ou simples declínio da religião (Luhmann 2002:284). É a forma como a religião observa o mundo social circundante que se ordena por critérios não religiosos, ou seja, a forma pela qual a religião designa seu outro lado: "Trata-se de uma descrição do outro lado da forma societal da religião, de uma descrição de seu ambiente societal interno [...] E trata-se de uma descrição feita por um observador específico, a saber, a religião; ou mais exatamente: de uma descrição da descrição do ambiente societal através deste, e somente deste, observador" (Luhmann 2002:282-283, tradução nossa).

Antes, portanto, de asseverar qualquer tendência sobre o destino da religião no mundo moderno, o conceito de secularização refere-se à própria concepção de mundo da religião em um ambiente societal que não se ordena segundo os desígnios religiosos. O núcleo generalizável do conceito de secularização é que ele designa um 
mundo social construído a partir de diferentes perspectivas sistêmicas de observação a partir de uma perspectiva específica: a da religião. Para Luhmann, assim como para Taylor, o conceito serve, em primeiro lugar, para apreender as condições sociais da fé na modernidade, privilegiando a ruptura com o mundo pré-moderno e pré-secular. A unidade do conceito é dada pela unidade das condições modernas da fé - a contingência da fé e das formas de vida e visões de mundo religiosas - que se instalam com o desmoronamento da sociedade estratificada em estamentos e da cosmologia integradora fornecida pela religião. $\mathrm{O}$ foco do conceito de secularização está, portanto, na transição à modernidade; a evolução societal posterior que afeta e reconfigura a relação religião-sociedade exige, por sua vez, outras categorias (como a de "secularidades múltiplas") capazes de apreender as variações resultantes da ressignificação social da diferenciação funcional e da secularização.

As formas pré-modernas de religião mantinham relações estruturais de interdependência tanto com a diferenciação estratificada como a entre centro e periferia. Na passagem à modernidade, essas relações estruturais assumem outro sentido, e a religião não é mais obrigada a recrutar seus "especialistas" na nobreza. Com o fim do primado da estratificação, a religião deixa de estar ontologicamente vinculada à ordem social hierárquica. Além disso, no nível da semântica (privilegiado por Taylor), esta transição afirma-se com a destruição dos correlatos cósmicos da sociedade ontologicamente hierarquizada (em estamentos): a sociedade não se concebe mais como um sistema sustentado pelo mundo. Os sistemas parciais que emergem com a diferenciação funcional não se deixam mais descrever como partes de um mundo unificado por uma cosmologia açambarcante de essências (Essenzkosmos); eles criam, ao contrário, seus próprios "mundos". Enquanto no mundo pré-moderno, a religião concebia monopolisticamente o mundo para todos os demais sistemas sociais (Luhamnn 1996:218), na sociedade moderna funcionalmente diferenciada o mundo é fragmentado pelas diferentes perspectivas sistêmicas, e a religião reage a isso descrevendo a sociedade e o mundo como secularizados. Secularizada é, pois, a representação, elaborada da perspectiva da religião, de uma sociedade que não se enquadra no ordenamento ontológico religioso (Luhmann 2002:289). Dito de outro modo: é a representação que a religião faz de um mundo cujo ordenamento e interpretação não é mais seu monopólio. Como se pode notar, ainda que Luhmann privilegie a dimensão da diferenciação societal negligenciada por Taylor, os dois autores convergem em conceber a secularização como o conjunto de condições da vida religiosa em um mundo que escapa e frequentemente se opõe à religião. A nosso ver, esta convergência no resultado indica que os dois caminhos teórico-metodológicos são muito mais complementares do que dissonantes.

Secularização pressupõe que a filiação e o grau de engajamento com a religião se tornem matéria de decisão. Trata-se de uma forma de atribuição e autodescrição da ação religiosa que consolida, no plano das identidades individuais e coletivas, as condições modernas da fé, ou seja, o "quadro imanente" no qual crer e praticar uma 
religião aparece como opção. Com isso, todo e qualquer vínculo social de natureza religiosa (incluindo aí o status de membro de uma organização religiosa) assume a condição de um vínculo contingente. A vida religiosa não pode mais ser fundamentada na natureza humana ou em qualquer forma de pertença coletiva definida de modo essencialista; agora a garantia última da convicção religiosa é a vivência individual (Luhmann 2002:293). Não se trata, porém, de uma individualização unilateral da inclusão religiosa. Esta individualização, na medida em que representa também a destruição dos suportes ontológicos da fé, é acompanhada pela necessidade crescente e constante de suporte e apoio social. Compartilhar convicções de fé não é mais algo dotado de uma existência "espontânea", que se pode pressupor a partir da essência ontológica das pessoas. No decorrer das trajetórias individuais de vida, a individualização biográfica da inclusão religiosa somente pode encontrar suporte e apoio social por meio

da construção visível e demarcável de comunidades, nas quais a fé encontra confirmação social, mesmo que outros não partilhem esta fé ou tenham outra fé. Na sociedade moderna, compartilhar convicções é um fenômeno excepcional, uma experiência que se destaca, agradável, e que pode levar os indivíduos a se juntarem a um grupo no qual se pode contar com a reedição desta experiência (Luhmann 2002:295-296, tradução nossa).

Nem mesmo os fenômenos religiosos fortemente engajados com um discurso de negação da condição secular e da própria diferenciação funcional podem escapar à necessidade de construir suporte social para a fé religiosa em uma sociedade que não é ordenada exclusivamente pela religião, ou seja, secularizada. Na dimensão das práticas sociais, a diferenciação funcional e a condição secular impõem-se mesmo àqueles que no plano discursivo se voltam contra elas:

Fundamentalismos de diferentes tipos, revivalismos, renovação da fé por meio de encenações sagradas, novos misticismos, etc., podem ser explicados a partir da intensidade do engajamento que produzem: condicionados pela secularização, estes diferentes movimentos e organizações religiosas voltam-se contra a secularização. Eles estão baseados menos nas próprias fontes históricas, que atualizam de modo fundamentalista, do que nas condições modernas que lhes oferecem a oportunidade de uma oposição (Luhmann 2002:295-296; tradução nossa).

A condição secular não consiste na convergência de trajetórias regionais de desenvolvimento em direção a um mesmo modelo de estruturar a relação entre religião e sociedade, mas sim no ponto de partida comum para a formação de diferentes 
formas de vida religiosas. Desse ponto de partida resulta uma modernidade religiosa marcada pela variação das formas de organizar tanto a esfera religiosa propriamente dita como sua relação com as demais esferas sociais. Algumas dessas formas têm se mostrado especialmente vigorosas. É o caso, por exemplo, do pentecostalismo evangélico em sua capacidade de ignorar soberanamente processos de exclusão social que afetam os indivíduos em outros sistemas funcionais e incluí-los de forma estável na vida religiosa (Luhmann 2002:307). Para Luhmann, essa forma de religião é grande candidata a desdobrar a potência social da religião na sociedade moderna. Mesmo que seja necessário sempre lembrar que toda mudança evolutiva só é acessível retrospectivamente (Luhmann 2002:318), o êxito de modelos organizacionais e formas de estruturação interna da esfera religiosa, tais como os do pentecostalismo, na configuração de uma dinâmica global de difusão e imitação (ainda que comportando variações) mostra que o fator organização é decisivo na definição do que será a modernidade religiosa do futuro.

Em seguida, veremos como a centralidade das organizações e da diferenciação funcional para a definição da condição secular produziram uma globalidade religiosa que afeta de modo estrutural todo tipo de prática ou crença religiosa que busque continuar existindo no mundo atual. Essa globalidade religiosa, produzida, ampliada e reproduzida sobretudo pela atuação e pela observação e imitação mútuas entre as organizações religiosas, representa a condição moderna da religião, definida pelo caráter global da diferença societal entre religioso e não religioso, ou seja, pelo caráter global da própria condição secular.

\section{A globalidade da condição secular}

Como ressalta Tobias Werron (2007:382), a pesquisa sobre sociedade mundial inspirada na teoria dos sistemas tem se concentrado quase exclusivamente em "estudos de transição" que descrevem apenas a passagem para a sociedade funcionalmente diferenciada na Europa entre os séculos XVI e XVIII. Há, deste modo, um déficit em "estudos de expansão" que tratem da globalização dos sistemas funcionais, ou seja, de sua expansão para outras regiões do globo, especialmente nos séculos XIX e XX. Diferentemente de Luhmann, Werron e Heintz (2011) não pressupõem que a diferenciação e a constituição de sistemas funcionais levam automaticamente à construção de uma ordem societal global. A globalização dessa forma de diferenciação é improvável e contingente. Por isso é necessário se perguntar pelas condições específicas que devem ser encontradas para que os sistemas funcionais desdobrem dinâmicas globais. Neste sentido, Werron e Heintz diferenciam processos fáticos de interconexão entre unidades sociais espacialmente separadas de dinâmicas globais baseadas na observação comparativa de fenômenos sociais específicos de cada sistema funcional, dinâmicas estas que descolam esses fenômenos de suas condições locais de surgimento e criam horizontes de comparação potencialmente globais para os sistemas funcionais: 
Concentramo-nos neste segundo aspecto da globalização e defendemos a tese de que ela se realiza, em primeiro lugar, por meio de comparações, e com isso queremos dizer comparações comunicadas. Um exemplo disso são os rankings de universidades que colocam em relação todas as universidades do mundo sem que estas estejam necessariamente interligadas de forma estrutural. Por comparação entendemos instrumentos de observação que produzem uma relação entre unidades (p. ex. pessoas, estados ou organizações) ou operações (p. ex. citações, competições esportivas ou exposições de artes). A comparação baseia-se, por um lado, na premissa de que as unidades comparadas são iguais em pelo menos um aspecto fundamental (produção de comparabilidade), e pressupõe, por outro lado, um critério de comparação que torne observável a diferença do que é (parcialmente) igual (Werron \& Heintz 2011:361-362, tradução nossa).

A tese de Werron e Heintz é que processos fáticos de globalização só podem ocorrer quando a produção local de operações sociais funcionalmente diferenciadas se orienta por horizontes que transcendem o local, ou seja, quando o sentido destas operações é coproduzido por horizontes não locais de referência e comparação. Decisivo aqui é o fato de que as práticas e unidades sociais orientadas por esse horizonte não local tomam como referência um público anônimo de destinatários que potencialmente pode abarcar o mundo todo. Sistemas funcionais superam suas fronteiras locais e territoriais na medida em que se criam e se institucionalizam "discursos públicos de comparação" (Werron \& Heintz 2011:365). Isto significa que a globalização dos sistemas funcionais se torna provável quando o sentido (a capacidade de conexão) das operações sistêmicas (desembolsos, decisões jurídicas, decisões políticas, competições esportivas, resultados de pesquisa, conversões religiosas, etc.) e a reprodução das unidades sociais responsáveis por produzir essas operações também forem determinadas por um horizonte de comunicações comparativas (avaliativas, críticas, etc.) produzidas por um público desconhecido e que não pode ser delimitado territorialmente.

Trata-se de um horizonte de possíveis relações/conexões entre comunicações produzidas por endereços sociais (a eles atribuídas) desconhecidos e separados tanto espacial como temporalmente. Para a ciência, por exemplo, basta "que existam a pretensão e a possibilidade de relacionar a própria pesquisa com outros trabalhos, independentemente de onde, quando e por quem estes são produzidos" (Werron \& Heintz 2011:367, tradução nossa). Comparações produzem globalização, independentemente da existência ou inexistência de contatos e redes de contatos.

Orientar-se por um público anônimo que compara, avalia e critica práticas sociais conduz a uma situação (a globalidade) em que antecipar as reações do público é um dos recursos comunicativos mais importantes, o que implica dizer que a prática social se descola para um plano de observação de segunda ordem (Werron \& Heintz 2011:375-378). Dito de outro modo: somente enquanto observação de segunda or- 
dem, como exemplificam as tabelas no sistema esportivo e os rankings de universidades no sistema científico, é que a concorrência e a cooperação entre ausentes se tornam possíveis (Werron \& Heintz 2011:367).

Para Werron e Heintz (2011), desde a segunda metade do século XIX surgem comunicações comparativas (fundadas na observação de segunda ordem) potencialmente globais que vão permitir estabilizar expectativas sobre comunicações e relações de concorrência e cooperação entre unidades sociais em diferentes sistemas funcionais ausentes espacialmente.

Sistemas funcionais globais existem quando suas operações e as unidades sociais orientadas por seu código valorativo (sobretudo as organizações) tomam como referência um sentido de possibilidade que transcende todo tipo de conexão local: "É imanente a esta lógica que toda operação sistêmica projete o mundo inteiro como horizonte de comparação" (Werron \& Heintz 2011:382, tradução nossa). O critério não é a existência de comunicações exteriores às fronteiras locais - o que certamente não é um dado exclusivo da modernidade -, mas sim o surgimento de uma lógica de expansão fundada na comunicação comparativa entre ausentes.

A tese desta seção é que este conceito de globalização igualmente se aplica ao sistema funcional da religião. $\mathrm{O}$ mecanismo que funda a globalidade religiosa também é a formação de uma esfera global de referências e práticas comparativas que afetam diretamente distintas religiões, difundindo, além disso, padrões de adaptação organizacional a racionalidades sistêmicas "mundanas" que tornam a secularização uma categoria universal. A esfera religiosa global baseia-se em operações estruturadas de observação e comparação que integram as diferentes religiões e organizações religiosas em um mesmo e único universo de busca por fiéis.

Os movimentos missionários cristãos que emergem do século XIX em diante foram decisivos para a construção dessa globalidade da esfera religiosa. A história global (Bayly 2004) dá conta de relações de reconstrução e transformação mimética das religiões a partir do contato com missões cristãs. A relação de antagonismo, ao invés de impedir, favorece o processo imitativo e a crescente integração da esfera religiosa global (Petzke 2013:14). No cristianismo do século XVII encontram-se as primeiras autodescrições de uma paisagem religiosa que levanta a pretensão de totalidade de sua perspectiva. Aqui se cristaliza um conceito de religião que não se refere apenas a uma religião específica. Mas isso foi esporádico, sem nenhuma consequência estrutural significativa para a construção de uma efetiva globalidade religiosa baseada em observação mútua institucionalizada. Assim como em outros sistemas funcionais, é somente no século XIX que a institucionalização da observação mútua de segunda ordem (a observação da observação do outro) leva à construção de uma esfera religiosa global. Apenas com as missões cristãs do século XIX é que esse tipo de observação adquire um caráter duradouro, operando por uma lógica estatístico-populacional e atraindo a atenção dos atores em virtude da circulação contínua dos fiéis pelas diferentes organizações religiosas (Petzke 2013:18). As distintas religiões constituem 
a diferenciação segmentar interna da esfera religiosa global, dinamizada pela busca de fiéis no horizonte global de possibilidades de conversão.

O pentecostalismo norte-americano é de especial interesse, pois foi a base da atividade missionária responsável pela globalidade religiosa nascente. Para Casanova (2008), trata-se do primeiro e paradigmático caso histórico de uma cultura global, não territorial e descentralizada. Como consequência da expansão do pentecostalismo missionário norte-americano, a concorrência e o pluralismo religioso são projetados no mundo. Outras religiões passam a ser observadas e a se auto-observar sob o ponto de vista da concorrência, como religiões com membresia exclusiva formada por atos contingentes e reversíveis de conversão. Desde o século XIX, esta perspectiva de observação totalizante está apoiada no ato da conversão, levando a que toda mobilidade religiosa seja atribuída a esse ato, inclusive em religiões não cristãs: "Apoiado na perspectiva de observação da cristandade evangélica pentecostal esboçada acima emerge um sistema global produtor de sentido: toda as 'conversões' em todas as religiões do mundo contribuem na reprodução de um horizonte de possibilidades, o qual, por sua vez, cria novas condições de partida para outras conversões e empreitadas missionárias" (Petzke 2013:19, tradução nossa).

O papel das empreitadas missionárias na institucionalização de uma esfera religiosa global pode ser identificado também nas convergências inter-religiosas decorrentes da difusão de modelos de adaptação organizacional da religião ao horizonte de possibilidades de conversão. Correntes do Islã, do Hinduísmo, do Budismo e também do Catolicismo construíram organizações com o objetivo de promover ou evitar conversões. Estas, ao estruturarem suas práticas a partir do objetivo missionário, se veem obrigadas a se adaptar a um mundo secularizado. Exemplo disso é a adoção, por parte dessas organizações, da lógica não religiosa da esfera dos meios de comunicação de massa, especialmente o uso calculado do saber publicitário na busca de fiéis.

Boa parte das teses mais recentes sobre a relação entre religião e modernidade não dá a devida importância à dimensão mesossociológica das organizações religiosas. É o caso, por exemplo, da tese da privatização da ação religiosa (Luckmann 1991). Nestas concepções, a relação entre o indivíduo e a religião não é percebida como uma relação mediada por organizações. Para Petzke e Tyrell (2012), trata-se de uma abordagem eurocêntrica que toma o caso de alguns poucos países europeus, nos quais as organizações religiosas vivenciam crescente declínio, como sendo $a$ expressão da modernidade religiosa. Para corrigir esse viés, seria necessário exatamente tomar o caso do campo religioso global constituído a partir da dinâmica interna das denominações missionárias norte-americanas como expressão mais fidedigna da religião na modernidade.

Ao contrário do caso europeu, a dinâmica de desregulação, concorrência, pluralismo denominacional e individualização da vida religiosa norte-americana seria marcada, entre outras coisas, pela combinação bem-sucedida entre racionalidade organizacional e "vitalidade religiosa" (Chang 2003:128ss). Quando se leva em conta a mobilidade religiosa e o trabalho missionário enquanto expressões comportamentais 
típicas de um ambiente de concorrência denominacional pela conversão ou reconversão do público de fiéis, temos a nossa frente um objetivo organizacional de natureza religiosa (a busca pela conversão de fiéis) que favorece, ao mesmo tempo, inovações estratégicas por parte das denominações que competem pelo público religioso. Neste sentido, pode-se dizer que o caso americano (muito semelhante ao caso brasileiro em sua configuração mais recente) é paradigmático enquanto solução para o problema da tensão entre religião e mundo no nível meso das organizações religiosas, já que racionalidade estratégica organizacional e objetivos religiosos estabelecem uma relação de reforço mútuo, permitindo com que a religiosidade das organizações seja mantida e ampliada mesmo com sua ênfase necessária em critérios não religiosos (como ocupar espaços na mídia ou mesmo a sustentabilidade econômica das denominações) de sucesso. Podemos dizer que essa forma organizacional, em razão da combinação bemsucedida da lógica religiosa com outras racionalidades sistêmicas e de sua afinidade com o desenvolvimento de uma esfera religiosa global aberta à competição, é uma das principais (senão a principal) representantes da modernidade religiosa. Seu potencial de desenvolvimento em uma sociedade mundial secularizada pode ser facilmente atestado quando se leva em conta o enorme êxito no pentecostalismo brasileiro em sua expansão pelo sul global ${ }^{4}$.

Esta realidade empírica de evolução, vitalidade e adaptação das organizações religiosas, que as torna capazes de adotar e desenvolver racionalidades estratégicas adequadas às referências não religiosas incontornáveis em uma sociedade mundial funcionalmente diferenciada em favor de objetivos e interesses especificamente religiosos, não está em contradição com o caráter global da diferenciação entre religioso e não religioso. Ao contrário: é justamente a globalidade dessa diferenciação que explica a difusão de modelos organizacionais talhados para lidar com a condição incontornável de organizar a ação religiosa em um mundo também estruturado por referências e lógicas autônomas como as da economia, da política, da ciência, dos meios de comunicação de massa, etc.

\section{Considerações finais: entre unidade e variedade da condição secular}

O argumento central desenvolvido neste texto é o de que a condição secular moderna adquiriu validade universal com a constituição de uma sociedade mundial fundada no primado da diferenciação funcional. Ele pode ser desdobrado em duas assertivas sobre a relação entre religião e sociedade no mundo moderno: 1) a diferenciação funcional da sociedade implica, para a esfera religiosa, a necessidade de se relacionar com um mundo social ordenado por critérios não religiosos, e o conceito de secularização designa precisamente a forma como a religião observa esse mundo societal; 2) como a diferenciação funcional se tornou um fenômeno global, vivemos em uma única e mesma sociedade mundial na qual toda e qualquer religião é obrigada a se relacionar com um mundo social secularizado. É isto que chamamos de universalidade da condição secular. 
Não se trata apenas da relação entre Igreja e Estado, mas também da relação com outras esferas não religiosas como a educação, os meios de comunicação de massa, a economia e a família. A fórmula mais abstrata é a seguinte: toda e qualquer religião é obrigada a se relacionar com a diferença entre religioso e não religioso enquanto traço incontornável da sociedade mundial. Quando organizações fundamentalistas como o "Estado Islâmico", ao lado do discurso de negação da condição secular e da diferenciação funcional como um todo, adotam uma estratégia de propaganda midiática calculadamente endereçada a um público global em sua alcançabilidade, estamos diante de uma forte evidência empírica favorável ao nosso argumento: é inexorável, para toda religião organizada voltada para a busca de fiéis, ter que se adaptar a racionalidades sistêmicas de natureza não religiosa. Como observam Wohlrab-Sahr e Burchardt (2012:882, tradução nossa): "A rejeição de conceitos como o de secularização ou secularismo em muitos lugares do mundo islâmico não está necessariamente ligada à ausência de diferenciações entre o religioso e o secular".

A universalidade da condição secular é, portanto, a universalidade da diferença entre religioso e não religioso instituída pela diferenciação funcional da sociedade, e não a universalidade de qualquer discurso ou ideologia secularista. Existe modernidade sem discurso ou ideologia secularista, mas não sem secularização. Para Taylor (2007), a universalidade da condição secular decorre da expansão global do "quadro imanente" que torna toda e qualquer crença e prática religiosa uma forma de vida opcional e contingente, impossibilitando que a religião seja vivenciada "ingenuamente" como incontornável e ancorada na própria estrutura do mundo. Para Luhmann, essa universalidade resulta da própria diferenciação funcional que torna a vida religiosa opcional. Enquanto que em sociedades pré-modernas era impensável participar da vida social sem participar da vida religiosa, na sociedade moderna isso é uma possibilidade real, contra e com a qual a crença religiosa precisa se afirmar e se reproduzir (Luhmann 2002:317).

No entanto, é de extrema importância delimitar o lugar do conceito de secularização. $\mathrm{O}$ conceito designa o ponto de partida da vida religiosa na sociedade moderna, o novo "terreno", por assim dizer, a partir do qual a modernidade religiosa se desenvolve (Luhmann 2002:307). Não designa o desenvolvimento e as variações da modernidade religiosa, ou seja, o ponto de chegada das diferentes realidades que resultam das distintas formas institucionais e culturais com as quais as religiões buscam se adaptar à universalidade da condição secular. O conceito de secularização não fornece, portanto, hipóteses explicativas sobre as formas assumidas pela relação entre religião e as outras esferas sociais em cada contexto concreto.

Uma interessante abordagem que busca dar conta dessas pretensões explicativas é a concepção de "secularidades múltiplas" (Wohlrab-Sahr \& Burchardt 2012). A ideia central é combinar a unidade da condição secular com a variedade das formas pelas quais a diferença entre a esfera religiosa e as esferas mundanas é interpretada e institucionalizada em diferentes regiões e países. Embora as religiões, em variados 
contextos, sejam obrigadas a "enfrentar" a diferença entre a esfera religiosa e as esferas não religiosas, o significado cultural e as formas institucionais que orientam esse "enfrentamento" variam de acordo com diferentes ideias-forças que se tornam dominantes na história dos distintos países e regiões. Tais ideias-forças se formam a partir da preocupação sistemática com problemas de referência específicos, que embora relacionados à diferença universal entre as esferas religiosa e não religiosa, adquirem mais importância em alguns países e regiões do que em outros, definindo assim o núcleo estrutural das "secularidades múltiplas".

A questão fundamental responsável por orientar a identificação das distintas "secularidades" é a seguinte: secularidade para quê? A tipologia oferecida por Wohlrab-Sahr e Burchardt distingue entre quatro casos: 1) secularidade em favor da liberdade individual, inclusive da própria liberdade religiosa, face a unidades sociais e ao próprio Estado, sendo os Estados Unidos o caso típico; 2) secularidade em favor da tolerância e do convívio pacífico entre as religiões, priorizando o direito de grupos e não a liberdade individual, sendo a Índia o exemplo paradigmático atual; 3) secularidade em favor do progresso nacional, entendido a partir de um consenso republicano que objetiva retirar a religião do espaço público, sendo a laicidade francesa (ao lado da comunista) o caso típico; e 4) secularidade em favor da autonomia dos demais sistemas funcionais em face da religião. Aqui a ênfase é na emancipação de esferas sociais do controle eclesiástico. E não é apenas a esfera política que vemos envolvida neste processo; também a educação, a medicina, o direito e as artes compõem o quadro de esferas para as quais secularidade significa, em primeiro lugar, autonomia perante os imperativos da fé religiosa. Em geral, esta última variante da secularidade é sustentada por grupos profissionais de distintas esferas (professores, médicos, artistas, cientistas, etc.) que lutam diferentes "batalhas" pela autonomia de sua esfera, assumindo raramente a forma de um projeto político explícito e unificado. Por isso, está presente em diferentes regiões e países (Wohlrab-Sahr \& Burchardt 2012:904).

Como a teoria da diferenciação funcional que serviu de base para definir e delimitar o conceito de secularização é livre de qualquer viés teleológico que assevere a difusão de um único modelo de relação entre religião e sociedade, ela parece plenamente compatível com a teoria das "secularidades múltiplas". Primeiro porque, assim como a outra, esta última também identifica que a prática de diferenciar a esfera religiosa das esferas mundanas se afirmou como universal para todas as regiões, países e culturas, inclusive para aqueles que rejeitam a diferenciação funcional no plano discursivo. Em segundo lugar, a teoria das "secularidades múltiplas", da mesma maneira que a teoria das "modernidades múltiplas" a qual lhe serve de inspiração, não formula suas hipóteses explicativas apenas com base na herança cultural dos diferentes países e regiões, conferindo grande importância às interconexões globais entre as diferentes formas de secularidade. Semelhante ao que acontece com a globalização dos sistemas funcionais, as interconexões entre as "secularidades múltiplas" baseiam-se no fato de a referência e a interação mútua entre elas transcenderem fronteiras territoriais, 
fazendo com que, por exemplo, as formas europeias de secularidade se tornem relevantes também para os países que a ela se opõem: "A centralidade destas interações decorre de que, no uso público da distinção entre religião e não religião, algum tipo de referência e relação com as formas europeias e ocidentais de modernidade e secularidade está sempre presente" (Wohlrab-Sahr \& Burchardt 2012:885, tradução nossa). Essa prática de referência (seja em termos de imitação, seja de rejeição) mútua produz um horizonte de possibilidades de articulação da vida religiosa com a vida social não religiosa que só pode ser pensado em termos globais. Na verdade, embora algumas formas de secularidade se tornem dominantes em determinados contextos, não se pode fazer assertivas sobre supostas identificações ontológicas desses contextos com formas específicas de imaginar e organizar a relação entre religião e sociedade secularizada. Em razão de suas interconexões, todas essas formas de secularidade estão efetivamente disponíveis no estoque de saberes dos diferentes países e regiões (Wohlrab-Sahr \& Burchardt 2012:892).

A compatibilidade da teoria da diferenciação funcional com a abordagem das "secularidades múltiplas" não significa que outras abordagens sejam incompatíveis com a teoria da sociedade de Luhmann para explicar a modernidade religiosa. As abordagens que diferenciam entre "modernidade central" e "periférica" são, por exemplo, extremamente úteis quando se trata de associar os níveis elevados de exclusão social - como um traço predominante da modernidade econômica, política e educacional de países periféricos - ao vigor de determinadas religiões como o neopentecostalismo. No entanto, quando consiste em qualificar o sistema religioso em si a categoria de periferia parece insuficiente. Embora nos ditos países periféricos a condição periférica predomine na maioria dos sistemas funcionais, inclusive no plano da autocompreensão e da autodescrição dos atores e organizações, o vigor da modernidade religiosa desses países (o Brasil é exemplar neste sentido) desautoriza o uso da categoria de periferia para essa esfera específica. A condição periférica não é um destino definido territorialmente, como se todos os sistemas funcionais em um país econômica, científica e politicamente periférico seguissem a mesma dinâmica de reprodução da diferença centro-periferia. $\mathrm{O}$ exemplo brasileiro mostra que o centro da modernidade religiosa, inclusive em termos de adaptação da religião à condição secular, não converge, por exemplo, com os centros da modernidade econômica. Ora, se na esfera religiosa, o centro pode estar na periferia, a abordagem das "secularidades múltiplas” parece mais adequada do que a abordagem da modernidade periférica. Mas vale enfatizar: mais adequada para a esfera da religião.

\section{Referências Bibliográficas}

BAYLY, Christopher A. (2004), The Birth of the Modern World, 1780-1914: Global Connections and Comparisons. Oxford: Blackwell Publishing. 
BERGER, Peter. (1967), The Sacred Canopy. New York: Double-day.

CASANOVA, José. (2008), "Public Religions Revisited". In: H. de Vires (ed.). Religion: Beyond a Concept. New York: Fordham University Press.

. (2010), "A secular age: dawn or Twilight". In: M. Warner et al. (eds.). Varieties of secularism in a secular age. Cambridge: Harvard University Press.

CHANG, Patricia M. Y. (2003), "Escaping the Procrustean Bed. A Critical Study of Religious Organizations, 1930-2001". In: M. Dillon (ed.). Handbook of the Study of the Sociology of Religion. Cambridge: Cambridge University Press.

EISENSTADT, Shmuel. N. (2000), Die Vielfalt der Moderne. Weilerswist: Velbrück Wissenschaft. GEYER, Carl-Friedrich. (1982), "Das Jahrhundert der Theodizee". Kant-Studien, no 1-4: 393-405.

KOENIG, Mattias. (2011), "Jenseits des Sekularisierungsparadigmas? Eine Auseinandersetzung mit Charles Taylor". Kölner Zeitschrift für Soziologie und Sozialpsychologie, no 4: 649-673.

LUCKMANN, Thomas (1991), Die unsichtbare Religion. Frankfurt a.M.: Suhrkamp.

LUHMANN, Niklas. (1977), Funktion der Religion. Frankfurt a.M.: Suhrkamp. . (1996), Liebe as Passion. Zur Codierung von Intimität. Frankfurt a.M.: Suhrkamp. . (2002), Die Religion der Gesellschaft. Frankfurt a.M.: Suhrkamp.

PARSONS, Talcott. (1951), The social system. Toronto: Free Press. . (1974), O sistema das sociedades modernas. São Paulo: Pioneira.

PETZKE, Martin. (2013), Weltbekehrungen: Zur Konstruktion globaler Religion im pfingstliche-evangelikalen Bewegung. Bielefeld: Transcript Verlag.

PETZKE, Martin \& TYRELL, Hartmann. (2012), "Religiöse Organisationen”. In: M. Apelt \& V. Tacke (eds.). Handbuch Organisationstypen. Wiesbaden: Springer VS.

PIERUCCI, Antônio Flávio. (2008), "De olho na modernidade religiosa". Tempo Social, no 2: 9-16.

TAYLOR, Charles. (1992), Sources of Self: The Making of the Modern Identity. Cambridge: Cambridge University Press.

(2007), A Secular Age. Boston: Harvard University Press.

SCHNEIDER, Wolfgang Ludwig. (2011), "Religion und funktionale Differenzierung". In: T. Schwinn et al. (eds.). Soziale Differenzierung. Handlungstheoretische Zugänge in der Diskussion. Wiesbaden: VS Verlag.

WEBER, Max. (1989), "Zwischenbetrachtung. Theorie der Stufen und Richtungen religiöser Weltablehnung". In: Schriften 1915-1920. Tübingen.

WERRON, Tobias. (2007), "Publika. Zur Globalisierungsdynamik von Funktionssystemen”. Soziale Systeme, $\mathrm{n}^{\mathrm{o}}$ 1-2: 381-394.

WERRON, Tobias \& HEINTZ, Betina. (2011), "Wie ist Globalisierung möglich? Zur Entstehung globaler Vergleichshorizonte am Beispiel von Wissenschaft und Sport”. Kölner Zeitschrift für Soziologie und Sozialpsychologie, no 3: 359-394.

WOHLRAB-SAHR, Monika \& BURCHARDT, Marian. (2012), "Multiple secularities: toward a cultural sociology of secular modernities". Comparative Sociology, nำ 11: 875-909.

\section{Notas}

1 Os primeiros estudos de Luhmann sobre religião (1977) compartilhavam certo ceticismo sobre as possibilidades desta se afirmar como um sistema funcional ao lado de outros. Em Die Religion der Gesellschaft (2002), esse ceticismo desaparece.

2 Para Parsons $(1951,1974)$, todo sistema (social, psíquico, biológico) precisa de quatro funções para existir e se reproduzir: adaptação (Adaptation), realização de metas (Goal-attainment), integração (Integration) e manutenção de padrões latentes (Latency). Este modelo de quatro funções (AGIL) é 
aplicado em diferentes níveis de análise, desde a análise do sistema geral da ação (que não se reduz a sistema sociais) à análise da evolução e da constituição da sociedade moderna. No nível mais amplo do sistema geral da ação, dividido em quatro subsistemas, cabe ao sistema social a função integração (I), ao sistema cultural a função de manutenção de padrões de conduta latentes (L), ao sistema de personalidades a função de perseguição de metas $(G)$ e, finalmente, aos organismos comportamentais a função de adaptação (A). No nível mais específico da evolução e da constituição da sociedade moderna, a sociedade diferencia-se em quatro subsistemas funcionais responsáveis por desempenhar as funções de modo especializado: a integração (I) fica por conta da comunidade societária (equivalente à comunidade nacional); a adaptação por conta da economia (A); a realização de metas a cargo da política $(G)$; e a manutenção de padrões latentes (L) especializa-se como função própria do sistema cultural. O caráter dedutivo e teleológico da teoria da diferenciação funcional de Parsons consiste na assunção de que o surgimento de sistemas funcionais autônomos - como "aquisição evolutiva" definidora das sociedades modernas - resulta da especialização evolutivamente programada de funções sociais que já existiam antes de sua especialização, e não, como em Luhmann, na própria criação, contingente e acidental, de novas funções sociais.

3 Evidentemente, como Weber demonstra de forma sobeja em sua abordagem que relaciona religião e estratificação social, o pertencimento estamental pode favorecer o cultivo de ideias e práticas religiosas muito distintas, dependendo, em primeiro lugar, da atividade (militar ou administrativa, por exemplo) identificada com a noção estamental de vida honrada.

4 Neste sentido, a modernidade religiosa de países como o Brasil caracteriza-se pela emergência de movimentos religiosos que, como o pentecostalismo, nascem com o desafio de se adaptar a um mundo que escapa em larga medida ao ordenamento cultural e institucional da religião. Isto significa que as organizações religiosas, para angariar fiéis, precisam lidar com o fato de que a condução da vida dos indivíduos não pode ser completamente regulamentada por normas religiosas. No caso específico do Brasil, assistimos, pelo menos desde as quatro últimas décadas, a um processo de reconfiguração da forma como o campo religioso nacional se integra ao campo religioso global fundado na produção e reprodução de um horizonte de possibilidades de conquista de fiéis.

Recebido em outubro de 2015. Aprovado em março de 2016.

Roberto Dutra (robertodtj@gmail.com)

Professor da Universidade Estadual do Norte Fluminense Darcy Ribeiro (UENF). Doutor em Sociologia pela Universidade Humboldt de Berlim, Alemanha. Suas últimas publicações são O problema da desigualdade social na teoria da sociedade de Niklas Luhmann (Caderno CRH, 2014) e Funktionale Differenzierung, soziale Ungleichheit und Exklusion (Editora UVK, 2013). 


\section{Resumo:}

\section{A Universalidade da Condição Secular}

O objetivo deste artigo é reconstruir o conceito de secularização a partir da teoria da diferenciação funcional de Niklas Luhmann. Esta teoria fornece elementos robustos tanto para definir de forma precisa o conceito de secularização como também para apreender o seu significado para as relações entre religião e sociedade no mundo atual. A tese central é que a secularização deve ser concebida como a principal consequência da diferenciação dos subsistemas sociais para a vida religiosa, podendo ser definida como a necessidade, enfrentada por toda e qualquer religião deste mundo, de ter que construir suas crenças e práticas em um mundo ordenado por referências não religiosas.

Palavras-chave: Secularização, Modernidade, Diferenciação Funcional, Sociedade Mundial, Religião.

\section{Abstract:}

\section{The universality of secular condition}

The aim of this paper is to reconstruct the concept of secularization based on the theory of functional differentiation of Niklas Luhmann. This theory provides robust elements both to define precisely the concept of secularism but also to understand its meaning for the relations between religion and society in today's world. The central thesis is that secularization must be conceived as the main consequence of functional differentiation for religious life: it can be defined as the necessity, faced by any religion of this world, of having to build their beliefs and practices in a world ordered not only by religious references.

Keywords: Secularization, Modernity, Functional Differentiation, World Society, Religion. 